\title{
State and Trends in the Development of Organizations Applying Multilevel Business Model
}

\author{
PhD candidate Ralitsa Ninosheva \\ University of Economics - Varna, Varna, Bulgaria \\ ralica.ninosheva@ue-varna.bg
}

\begin{abstract}
In recent years, organizations, applying multilevel business model, have made significant progress in their development. It is conditioned by many factors. The concept of running business operations through these type of business model is still a little known business strategy. Low level of knowledge about the issue is most likely caused by lack of research and small amount of publications concerning the subject. This report examines current issues and data on the functioning of Multilevel business organizations and aims to provide an integrated overview of their development, in the context of the global market. The revealed trends can be used as a starting point for outlining the main problems and perspectives for the future of this form of business organizations.
\end{abstract}

Keywords: multilevel business model, trends, global market, direct sales

JEL Code: D61, E320, F430, M210, O32, O33; doi:10.36997/IJUSV-ESS/2019.8.3.171

\section{Въведение}

Мултилевъл бизнес (МЛБ) модельт е един от най-бързо развиващите се, успешно приложени форми за управление на съвременните организации (Failla, 2014). Той преминава географските, културните и възрастовите ограничения и не изисква специално образование, опит и финансови средства. Компаниите, прилагащи го, използват форми на структуриране и управление, които в голямата си част са различни от традиционните. В своята същност те представляват извънмагазина търговия за разпространение на стоки и услуги директно до крайния потребител. Разполагат с мрежи от независими участници, формиращи структурата и получаващи комисионни, както от своите лични продажби, така и от тези на хората, които са привлекли. Актуалността му до голяма степен произтича от средствата, които осигурява за справяне с последствията в условията на глобалния спад в икономиката, съкращаването на работни места, ниските заплати и несигурността относно доходи, спестявания, пенсионно и здравно осигуряване. Възможностите, които предоставя се свързват с ниски първоначални инвестиции, малък риск, развитие, на база на лични потребности, получаване на пасивен доход и предприемаческа перспектива.

Целта на настоящата разработка е да представи обобщен преглед на състоянието на МЛБ организациите в глобален аспект, да открои актуалните тенденции в развитието им и да представи перспективите, пред които са поставени.

\section{1. Еволюция в развитието на идеите за МЛБ моделите}

МЛБ моделът е известен още като мрежов маркетинг (network marketing) или мултилевъл маркетинг (multi-level marketing). Често се среща и под абревиатурата МЛМ (Albaum\&Peterson, 2011). Някой хора го асоциират и разглеждат под наименования като „маркетинг от уста на уста“, „маркетинг на взаимоотношенията“ и „интерактивни продажби“ (Hossan et. al., 2012). Според Асоциацията за директни продажби, много от компаниите, членуващи в нея, са организирани на принципа на МЛБ модела. На база на това „продавачите имат възможността, в допълнение към наградите от лични продажби, да изградят собствени екипи. По този начин те могат да получат допълнителни възнаграждения, които идват от продажбите, постигнати от тези, които са наели, обучили, подпомогнали и мотивирали“ (DSA, 2019).

Според Коуглън и Грейсън (1998) МЛБ организациите са „дружества, чиито доход зависи само или основно от директни продажби и чиито участници получават възнаграждение за: (1) закупуване на продукта или услугата; (2) продажба на продукта/услугата; (3) намиране 
на други участници, които купуват и продават продукти или услуги“ (Coughlan\&Grayson, 1998). Тази форма на организация на бизнеса има няколко основни характеристики (Coughlan\&Grayson, 1998), отличаващи я до голяма степен от традиционните:

- човешкият капитал - МЛБ организациите използват независими участници, които продават продуктите/услугите, вместо да наемат и управляват многоброен продажбен персонал (Kazmierczak\&Labuz, 2018).

- спестявания - не рекламират продуктите си в търговската мрежа и премахват веригата на доставките (Dimitrov, 2017).

- възнаграждение - участниците не получават заплата. Техните доходи зависят от комисионните от продажби както на собствените си продукти и услуги, така и на тези в непосредствените продажбени линии под тях.

- бизнес възможност - независимите участници избират - желаят ли да се развиват и да привличат и обучават нови лица за техните екипи, или са ориентирани единствено към продажбите.

Въпреки че МЛБ моделът е възприеман като сравнително нов феномен в бизнес средите, неговата основа се поставя още през средата на 40-те години на ХХв. Заражда се на база на директните продажби и постепенно бива утвърден като приоритетната им форма. Икономическото му значение представлява интерес за редица учени, сред които Джон Найсбит и Патрисия Абърдън (Naisbitt\&Aburdene, 1990), които представят четири етапа в неговата еволюция:

- пионерски етап (1945-1977) - успешно развитие на американски компании като Amway и Nutrilite, поява на МЛБ модела и развитието му в Европа и Азия;

- професионален етап (1977-1990) - увеличава се обема на продажбите и постепенно започват да се прилагат стратегии за създаване на мрежа от представители;

- информационен етап (1990-2000) - навлизане на информационните технологии, с помощта на които мрежата от представители започва да се наблюдава. Използват се иновативни методи за популяризиране и доставка на продуктите и услугите;

- етап на глобализацията (2000 - до момента) - все още е в ход и се характеризира с главоломно увеличение на обема на продажбите поради: разширяване на асортимента от продукти и услуги, нарастващ брой независими представители, големите финансови предимства и по-лесното проникване на международни пазари, използвайки Интернет.

Днес МЛБ организациите се намират в един много динамичен етап, с постоянно променящи се условия в средата. Непрекъснатото наблюдение на различни показатели и тенденции, определящи текущото им състояние и развитие ще е критичен фактор за техния успех в перспектива.

\section{2. Изследване и характеризиране състоянието на организациите, прилагащи}

\section{МЛБ модел в глобален аспект}

МЛБ организациите бележат все по-голям растеж и доказват своята конкурентоспособност през последните години. За 2018-та година приходите от директни продажби, в световен мащаб, достигат 192.9 милиарда долара. Наблюдава се устойчив темп на растеж с $1,7 \%$, за тригодишен отчетен период (вж. Фиг.1).

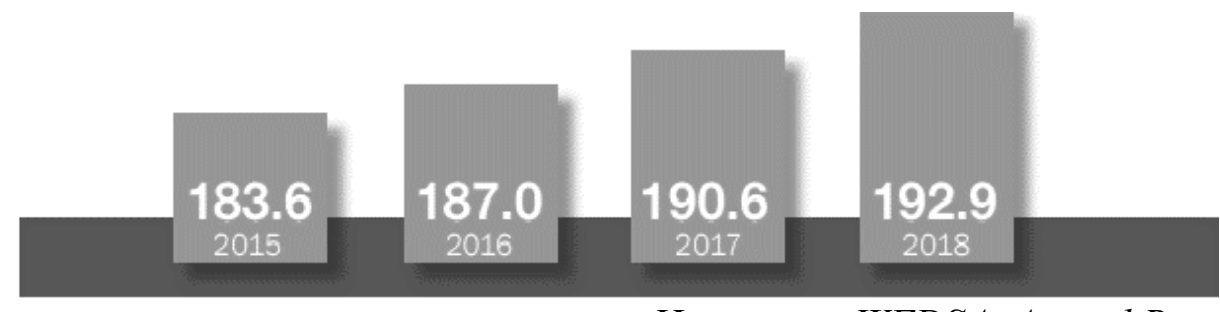

Източник: WFDSA, Annual Report - 2019

Фигура 1. Ръст на директните продажби в световен мащаб за периода 2015 - 2018 г. (в млрд.долари) 
Глобалната статистика сочи, че процентното отношение на директните продажби по региони, остава почти непроменено, спрямо 2015г.
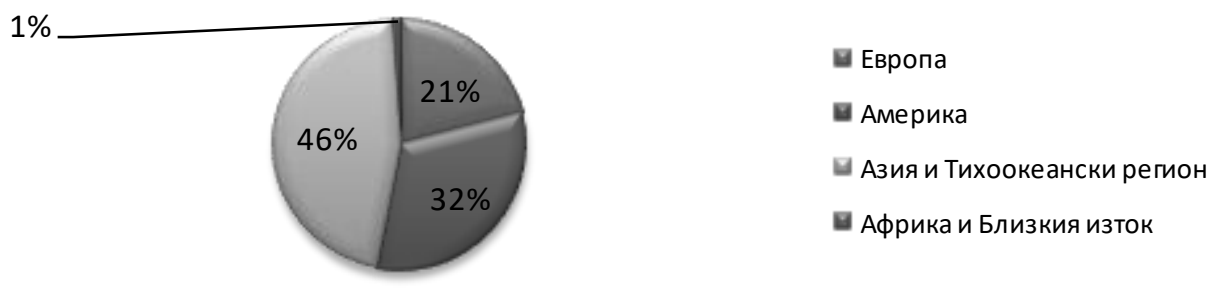

Източник: WFDSA, Global Direct Selling - 2018 Фигура 2. Процентно отношение на директните продажби по региони за 2018 г.

Азия и Тихоокеанската област остават най-големият в света регион, осъществяващ директни продажби с дял от 46\%. Сред всички останали, Европа е била най-бързо развиваща се през последните три години, като продажбите и нарастват от 16\% през 2012 г. на 21\% през 2018 г. В сравнение с нея, Северна и Южна Америка са изгубили 7\% дял от продажбите си за същия период (Makni, 2014). Като един развит пазар, този спад се дължи най-вече на пренаситеността му. Африка и Близкия изток държат по-малко от 1\% от световните продажби. Липсата на перспектива пред тях до голяма степен се дължи на бедността на населението, тежките условия на живот в Африка, както и на постоянните военни конфликти и масовата емиграция на хора. Броят на независимите участниците в директните продажби достига 118,4 милиона (вж. Фиг.3).
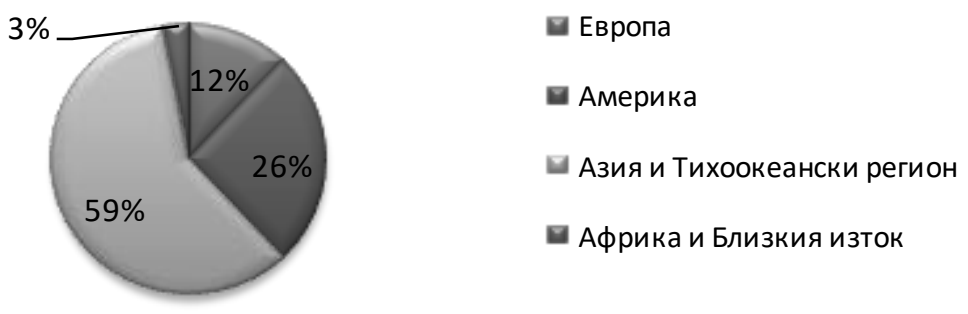

Източник: WFDSA, Annual Report 2019 Фигура 3. Процентно съотношение на участниците в директните продажби по региони за 2018 г.

Отбелязва се ръст с 4,2\% спрямо 2015 г. (вж. Фиг.4). Тенденцията бележи продължаващ растеж и за в бъдеще. Експерти смятат, че това се дължи на повишаване на предприемаческите нагласи и все по-голямото използване на директните продажби, и в частност МЛБ модельт от организациите. Дългосрочните перспективи за растеж пред директните продажби остават стабилни (виж Фиг.4)

Участниците в директните продажби са най-многобройни в Азиатския регион, като там достигат почти 70 милиона. В Америка те наброяват 31 милиона, а Европейските представители са с численост около 14,4 милиона. Най-малобройни са тези в Африка и Близкия изток - малко над 3 милиона души.

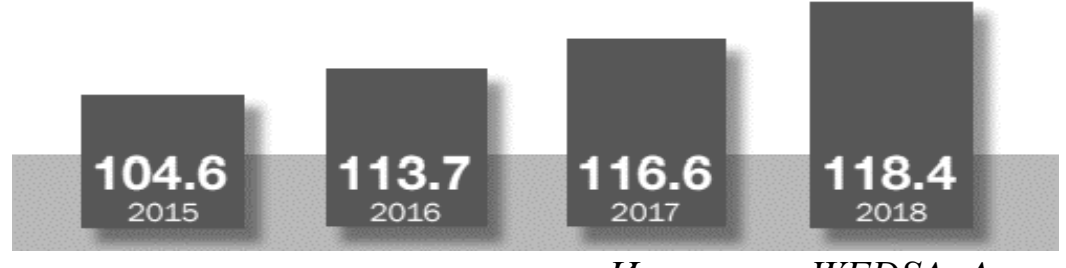

Източник: WFDSA, Annual-Report-2019

Фигура 4. Годишни темпове на нарастване на участниците в директните продажби в милиони за период 2015 - 2018 г. 
От всички участници в сферата на директните продажби за 2018 г. (WFDSA,2019):

$>10,5$ милиона са на пълен работен ден, отделяйки 30+ часа седмично;

> 42,9 милиона са на непълно работно време отделяйки до 30 часа седмично;

$>$ 64,9 милиона са тези, които са се присъединили, защото харесват продуктите или услугите и искат да ги използват с отстъпка. Тук се включват и неактивните участници. На таблицата по-долу са представени обобщени данни за директните продажби в милиони долари за съответните региони, процентната им промяна, спрямо предходната година и спрямо три годишен период, както и броят тьрговци, опериращи в тях.

Таблица 1. Продажби, процентно изменение и брой търговци в регионите за 2018 г.

\begin{tabular}{|l|c|c|c|c|}
\hline \multicolumn{1}{|c|}{ Регион } & $\begin{array}{c}\text { Директни продажби } \\
\text { за 2018 г. (млн.) }\end{array}$ & $\begin{array}{c}\text { \% промяна, } \\
\text { спрямо 2017 г. }\end{array}$ & $\begin{array}{c}\text { \% промяна за периода } \\
2015-2018 \text { г. }\end{array}$ & $\begin{array}{c}\text { Брой търговци } \\
\text { (млн.) }\end{array}$ \\
\hline В световен мащаб & 192,949 & $1.2 \%$ & $1.7 \%$ & $118,408,732$ \\
\hline Азия/ Тихоокеания & 89,168 & $1.8 \%$ & $1.9 \%$ & $69,725,723$ \\
\hline Африка/Близък Изток & 1,786 & $1.4 \%$ & $6.4 \%$ & $3,348,675$ \\
\hline Африка & 1,540 & $1.1 \%$ & $6.3 \%$ & $2,220,399$ \\
\hline Близък изток & 246 & $3.5 \%$ & $6.8 \%$ & $1,128,276$ \\
\hline Америка & 62,438 & $1.5 \%$ & $0.5 \%$ & $30,971,615$ \\
\hline $\begin{array}{l}\text { Централна и Южна } \\
\text { Америка }\end{array}$ & 25,140 & $2.0 \%$ & $2.3 \%$ & $13,194,615$ \\
\hline Северна Америка & 37,297 & $1.1 \%$ & $\mathbf{- 0 . 6 \%}$ & $17,777,000$ \\
\hline Европа & 39,558 & $\mathbf{- 0 . 3 \%}$ & $2.7 \%$ & $14,362,719$ \\
\hline Дьржави в ЕС & 35,204 & $\mathbf{- 0 . 1 \%}$ & $2.4 \%$ & $6,858,558$ \\
\hline Дьржави извън ЕС & 4,353 & $\mathbf{- 1 . 4 \%}$ & $6.1 \%$ & $4,721,663$ \\
\hline
\end{tabular}

Източник: Таблицата е съставена по данни на WFDSA, 2019

От представените данни ясно личи, че последната година се отбелязва спад в продажбите в регион - Европа. Въпреки това, в периода 2015 - 2018 г. тенденцията е там да се бележи ръст. Единствен от всички големи региони - Северна Америка има отрицателна стойност на продажби в дългосрочен период. Най-високо увеличение на директните продажби има в Африка и Близкия Изток, което е възприемчиво като се има предвид слабата наситеност на пазара, незаетата пазарна ниша и желанието за достьп до капитал.

Ако разглеждаме националните пазари, Китай измества САЩ и заема първа позиция, с годишни обеми на продажбите съответно 35,7 милиарда долара и 35,3 милиарда долара. Растежът на американския пазар през 2015 г. е 4.8\%, а на китайския -19\%. Тенденцията от тогава се запазва и промяната в челните места в пазара на директните продажби е на лице.

Десетте най-големи пазари, класирани заедно с дяловете им в глобалния обем са както следва: Китай (20\%), САЩ (19\%), Южна Корея (9\%), Германия (8\%), Япония (8\% Бразилия (5\%), Мексико (4\%), Франция (2\%), Малайзия (2\%) и Тайван (2\%) Според националните асоциации за директни продажби десетте страни първенци, генерират $79 \%$ печалба от глобалните директни продажби.

При разглеждането на категориите продукти и услуги, за 2018 година, най-голям дял заема уелнес услугите, с 33,2\%. С близък процент - 31,2\% от обема на глобалните продажби, го следва козметиката. На трето място са домакинските дълготрайни стоки с 12,8\% , а на четвърто - облеклото и аксесоарите с 6,2\% (вж. Фиг.6).

Уелнес услугите са най-разпространената категория световен мащаб. Тя отбелязва ръст спрямо козметичните продукти. Нарастващият интерес към пътуванията и здравословните процедури, води до инвестиране в сферата и все по-голяма използваемост на услугите в сектора. Нещо повече - според Американският неправителствен институт за изследвания (SRI Institute), „здравословното хранене и загубата на тегло, превантивното и персонализирано здравеопазване, допълващата и алтернативна медицина, както и процедурите за разкрасяване и против стареене, са най-бързо развиващите сектори“ (Kojuharov, 2014) през последните години. В действителност големият дял на Азиатско-Тихоокеанският регион се дължи на 
огромния интерес към уелнес услугите и здравословния начин на живот във Филипините $89 \%$, в Хонг Конг $-69 \%$ и в Тайван $-63 \%$.

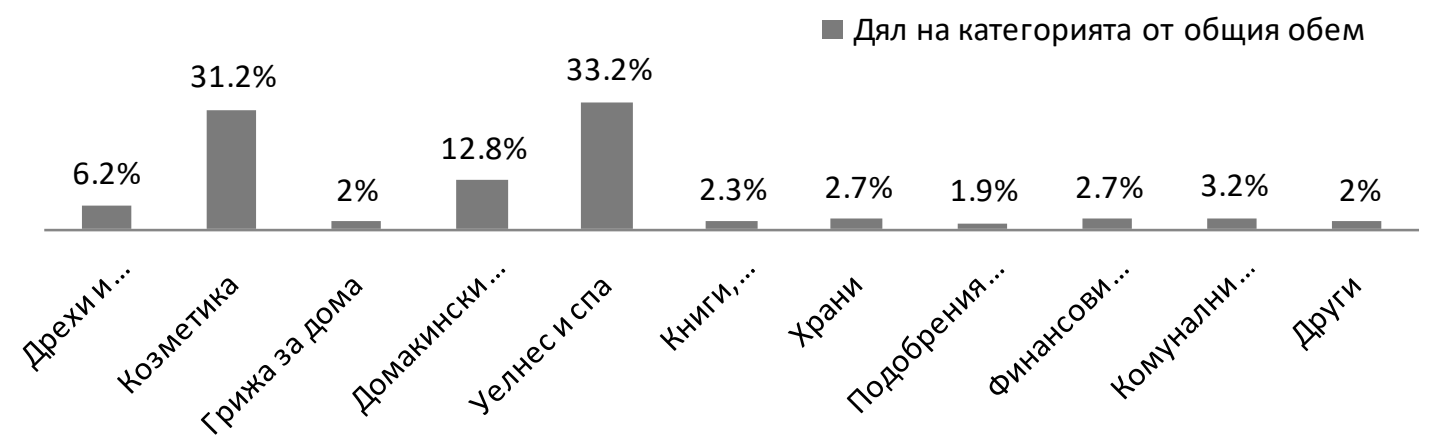

Източник: WFDSA, Annual Report 2019 Фигура 5. Процентно отношение на директните продажби по категории продукти за 2018г.

Що се отнася до категорията разкрасителни продукти (козметика), водеща е Америка с $35 \%$ от общия дял, следвана от Азия и Европа. По отношение на финансовите услуги, в повечето държави няма широко утвърдена практика да се предлагат на базата на МЛБ и директни продажби. Увеличение бележат категориите домакински дълготрайни стоки; книгите, играчките и канцеларските материали; храните; комуналните услуги; подобренията на жилищата.

В таблица 2 са посочени най-успешните компании за директни продажби в световен мащаб, според доклад на „Direct Selling News“.

Таблица 2. Топ 20 компании за директни продажби, генериращи найвисоки приходи за 2019 г. в световен мащаб

\begin{tabular}{|c|c|c|c|}
\hline $\begin{array}{c}\text { Номер в } \\
\text { класацията }\end{array}$ & Име на компанията & $\begin{array}{c}\text { Брой продажби } \\
\text { (млрд. долара) }\end{array}$ & Вид организация \\
\hline 1 & Amway & 8,80 & МЛМ \\
\hline 2 & Avon & 5,57 & МЛМ \\
\hline 3 & Herbalife & 4,90 & СЛМ/МЛМ \\
\hline 4 & Infinitus & 4,50 & МЛМ \\
\hline 5 & Vorwerk & 4,30 & МЛМ \\
\hline 6 & Natura & 3,67 & МЛМ \\
\hline 7 & Nu Skin & 2,68 & МЛМ \\
\hline 8 & Coway & 2.50 & СЛМ/МЛ \\
\hline 9 & Tupperware & 2,00 & СЛМ/МЛМ \\
\hline 10 & Young Living & 1.90 & МЛМ \\
\hline 11 & Oriflame Cosmetics & 1.55 & МЛМ \\
\hline 12 & Rodan + Fields & 1.50 & МЛМ \\
\hline 13 & Jeunesse & 1.46 & МЛМ \\
\hline 14 & Ambit Energy & 1.30 & МЛМ \\
\hline 15 & DXN Marketing Sdn Bhd & 1.25 & МЛМ \\
\hline 16 & Pola & 1.24 & СЛМ \\
\hline 17 & O Boticario & 1.23 & МЛМ \\
\hline 18 & USANA Health Sciences & 1.19 & МЛМ \\
\hline 19 & Belcorp & 1.16 & СЛМ \\
\hline 20 & Atomy & 1.15 & МЛМ \\
\hline
\end{tabular}

Източник: Таблицата е съставена по данни на “Direct Selling News”, 2019

\footnotetext{
${ }^{1}$ МЛМ - мрежов маркетинг, компании с директни продажби в мрежа, на няколко нива; СЛМ - компании, използващи представители на едно ниво.
} 
От представените данни ясно личи, че компаниите, преобладаващи в челните места на класацията, са устроени на принципа на МЛБ моделът. И не само - 18 от 20 компании функционират по този начин. Това е доста показателна статистика, описваща процентното съотношение между организациите, работещи с представители само на едно ниво $(10 \%)$ и тези, работещи с мрежа от екипи (90\%).

Интересно е да се отбележи, че преобладаващата част от търговците в сектора през 2018 г. са жени. Не случайно този бранш доста често е наричат ,розовата икономика“. Тенденцията е да заемат все по-голям процент от общия дял, който в момента е $74 \%$ в тяхна полза и едва $26 \%$ в полза на мъжете. Това е продиктувано най-вече от възможностите за бизнес, които се отварят пред тях, интереса към предлаганите продукти, както и алтернативата за допълнителен или основен доход, без да напускат домакинството.

Тенденция, която се забелязва през последните години, е преориентация на индустрията на директните продажби към развиващите се пазари и спад на инвестициите в зрелите и стабилни такива. Продажбите на пьрвите пазари съставляват 42,7\% от глобалните директни продажби и бележат значително увеличение за периода 2010 - 2019 г. - с 10,8\%. Обратнопропорционално на тях, тези на развитите пазари - 57,3\%, се характеризират с непрекъснат спад (WFDSA, 2019).

\section{3. Тенденции и перспективи през развитието на организациите, прилагащи МЛБ модел}

От направените характеристики на пазара на директни продажби и МЛБ организациите в него могат да се изведат актуални тенденции в управлението им:

$>$ МЛБ модельт продължава да се утвърждава като алтернатива за развитие на бизнес за организациите по целия свят. Глобалната му експанзия се свързва както с ниските бариери при навлизане и големите възможности, които предоставя, така и с развитието на Интернет.

$>$ Приоритетно се извършват инвестиции в развиващите се пазари, поради съсредоточаване на голяма част от населението там, бедността, желанието да се повиши жизнения стандарт и силата на семейните мрежи. ${ }^{2}$ Тази тенденция продължава да се развива.

$>$ Увеличават се заетите в МЛБ организациите, с приоритет жените. Те се възползват от предприемаческата възможност да развиват собствен бизнес, без голям риск и капиталовложения. По този начин те се „овластяват“ и стават независими. Това в пълна степен важи за развиващите се пазари, където често е налице липсата на равенство. Освен това, са основните потребители на продуктите и услугите, които се предлагат.

$>$ Насочване на потребителите към категориите продукти и услуги, които спомагат за опазване на здравето и поддържане на баланс в забързаното ежедневие.

Освен изведените на база на статистически данни тенденции, непрекъснатите промени в глобалната среда диктуват нови правила в бизнес средите. Те се появяват и утвърждават толкова бързо, че само най-конкурентоспособните оцеляват. Успешните организации са тези, които притежават способността да се приспособяват към промените. В тази връзка могат да се обобщят няколко тенденции, които в дългосрочен период са решаващи за успеха на МЛБ организациите.

- Обединяване на двата подхода „ориентираност към пазара“ и „ориентираност към клиента“. МЛБ организациите акцентират едновременно на качеството на предлаганите продукти на съответните пазари и на желанията на клиентите си. Уникалната връзка между двата подхода се състои в наблюдения и изучаване на нуждите на купувачите, провеждане на научно-изследователска дейност и създаването на най-добрите възможности за

\footnotetext{
${ }^{2}$ Азиатските семейства са склонни да бъдат по-сплотени географски, с повече случаи на множество поколения, които пребивават съвместно в един и същи град, област или дори къща.
} 
задоволяването на съответната нужда (Rezvani et. al., 2017). Не е изненадващо, че уелнес услугите е най-развитата категория, във времена в които желанието за предотвратяване на стареенето, здравословния начин на живот и отслабването са приоритети в глобален мащаб.

- Преориентация на заетите в МЛБ организациите. МЛБ организациите, традиционно осигуряват доходи при работа на непълен работен ден. Промяната е налице и се забелязва все по-голямо преориентиране към израстване в кариерата, именно чрез тази форма на организация. Много университети създават учебни програми, които помагат на студентите си да усъвършенстват комуникационните, мрежовите и презентационните си умения. Също така подготвят предприемачите за създаване на целеви МЛБ организации и разработване на продукти на корпоративно ниво.

- Използване на нови технологии. Днес технологиите влияят на начина, по който работи всеки един бизнес модел. Те му помагат да се развива с по-голяма скорост и МЛБ организациите не са изключение от правилото. Развитието им се съсредоточава в няколко направления:

- Промени в моделите на потребление. Хората от новите поколения прекарват средно по 10 часа пред екран (в социални медии, браузъри, сайтове и др.), търсейки висококачествени и устойчиви продукти. Ето защо МЛБ компаниите се адаптират към тези нужди чрез използване на технологични инструменти. Дигитализирането позволява на бизнеса да се разширява. Чрез въвеждане и прилагане на различни стратегии, социалните медии позволяват на МЛБ организациите да показват своите продукти/услуги, компенсаторни планове, цели и визия пред потребителите си. Технологичните инструменти включват: поддържане на сайт, достъп до всички социални медии и поддържане на висок имидж, поддръжка на цифрова валута, бизнес разузнаване, суб-акаунти и др.

- Използване на социализаџия чрез интернет. Тук говорим за организиране на онлайн социални срещи (най-често във Фейсбук), което дава възможност на "домакинът“ да кани хора и приятели, които живеят далеч, извън непосредствените си крьгове. „Виртуалното парти“, може да бъде отворено за няколко часа или в специално време в продължение на серия от дни, като предоставя на гостите гъвкавост относно присъединяването. Освен онлайн социални срещи, много от участниците в бизнеса използват интернет за провеждане на УЕБ семинари, чрез използване на безплатни приложения като Facebook LIVE и YouTube LIVE. Това им спестява време, усилия и най-вече разходи.

- Бързо и сигурно получаване на доход. С електронното банкиране, вече норма в нашата култура, изплащанията на комисионни към всяка продажба стават изключително бързо. Вместо да чакат до шест седмици за освобождаване на печалбата чрез хартиени чекове, МЛБ организациите използват приложения за електронни портфейли и дебитни карти, за да възнаградят продажбите си в рамките на дни. Банковите институции стават важен участник в МЛБ модела, тъй като до голяма степен гарантират спазването на регулаторните норми и предоставят надеждни и удобни възможности за плащане.

За да са конкурентоспособни МЛБ организациите все повече трябва да се ориентират към дигитализиране и по-голямо присъствие в интернет пространството. Поддържането и използването единствено на стари способи ще е критично за оцеляването на всички бизнес модели в бъдеще.

\section{Заключение}

МЛБ организациите достигат приходи от продажби в размер на 192,9 милиарда долара за 2018 година. Потенциалът им е огромен и се счита, че ще продължава да се развива, като по официални прогнози достигне размер от 625 милиарда до 2025 г. Тази статистика е обусловена от растежа на потребителските пазари и широката експанзия в глобален мащаб, но в голяма степен зависи и от създаването на благоприятна среда за този вид бизнес модел и смекчаване 
на някои от предизвикателствата, с които се сблъсква днес.

МЛБ организациите имат възможност да създадат значително социално и икономическо въздействие, особено в областта на овластяването на жените, развитието на уменията и технологиите, подкрепа на предприемачеството, насърчаване на самостоятелната заетост и осигуряването на жизнеспособни средства като алтернативен доход.

\section{References}

1. Albaum, G., Peterson, R. (2011) Multilevel (network) marketing: An Objective view. The Marketing Review, Vol. 11, pp. 347-361

2. Coughlan, A., Grayson K. (1998) Network marketing organizations: Compensation plans, retail network growth, and profitability. International Journal of Research in Marketing, Vol. 15, pp.401-426

3. Dimitrov, N. (2017) Mrejoviat marketing kato inovacionen biznes podhod. Conference: Problems and challenges of modern economy, University if Finance, Business and Entrepreneurship.

4. Direct Selling Association, Multilevel Marketing (MLM) or Network Marketing, Available from http://www.dsa.org.uk/about-the-dsa/what-is-direct-selling/, [Accessed 05/10/2019].

5. Failla, D. (2014) The 45-Second Presentation That Will Change Your Life. Volkson Books trading.

6. Hossan, F., Ahammad, I., Ferdous, L. (2012) A Conceptual Evaluation of Traditional and Multilevel Marketing, World Journal of Social Sciences. Vol. 2. №4, pp.34-43

7. Kazmierczak, J., Labuz, A. (2018) Multi-level Marketing. Features and Controversy. Annals of Marketing, Management and Economics, Vol. 4, pp.25-34

8. Makni, V. (2014) Direktni prodajbi I mrejov marketing: dinamika, struktura $i$ tendencii $v$ globalen aspect. Izvestia - izdanie na Ikonomicheski universitet - Varna, pp.16-30

9. Naisbitt, J., Aburdene, P. (1990) Megatrends 2000: Ten New Directions for the 1990's. William Morrow \& Co; 1 st edition.

10. Rezvani, M., Ghahramani, S., Haddadi, R. (2017) Network Marketing Strategies in Sale and Marketing Products Based on Advanced Technology in Micro-Enterprises. International Journal of Trade, Economics and Finance, Vol. 8, pp.32-37

11. WFDSA, Annual Report (2019), Available from https://wfdsa.org/download/advocacy/ annual_report/WFDSA-Annual-Report-2019.pdf [Accessed 05/10/2019].

12. WFDSA, Global Direct Selling (2015), Available from http://wfdsa.org/wp-content/uploads/ 2016/02/FINAL-Sales-Report-2015-v2-5-31-2016-002.pdf [Accessed 07/10/2019].

13. WFDSA, Global Direct Selling (2018), Available from https://wfdsa.org/wp-content/uploads/ 2019/06/Sales-Seller-Report-FINAL.pdf [Accessed 04/10/2019].

14. WFDSA, Sales Report (2018), Available from https://wfdsa.org/wp-content/uploads/ 2019/06/Sales-Seller-Report-FINAL.pdf [Accessed 07/10/2019]. 